\title{
Perception and quality of life of patients after surgery keratoconus
}

\author{
Percepção e qualidade de vida do paciente \\ após cirurgia de ceratocone
}

Anna Lúcia Costa de Miranda ${ }^{1}$, Laura Ligiana Dias Szerwieski ${ }^{1}$, Murilo Dziecinny Ferreira ${ }^{1}$, Marcelo Costa de Miranda ${ }^{2}$, Lucia Elaine Ranieri Cortez ${ }^{1}$

\begin{abstract}
Objective: To know the perception of the patient after surgery keratoconus. Methods: descriptive exploratory study with a qualitative approach. Data were obtained through audio-taped interviews with keratoconus patients undergoing surgery and the transcripts were subjected to content analysis, thematic modality. Results: Transcripts allowed the formation of two categories: Experiencing the disease and change of life after surgery. The first has listed the experience of patients with keratoconus, faced difficulties, mutatis mutandis, search for resources and frustrations and the second category highlights the concerns related to the surgical procedure, then the hope of finding the solution, and surgery considered as something miraculous, because allowed to return to society and brought back the meaning of existence. Conclusion: Patients undergoing keratoconus surgery reported that surgery has promoted the improvement of self-esteem and self-love, bringing back the meaning of life they had lost.
\end{abstract}

Keywords: Keratoconus/surery; Ambulatory, Surgical procedures; Quality of life

\section{RESUMO}

Objetivo: Conhecer a percepção do paciente após cirurgia de Ceratocone. Métodos: Foi realizado um estudo exploratório descritivo, com abordagem qualitativa. Os dados foram obtidos por meio de entrevistas áudio-gravadas, com pacientes submetidos à cirurgia de ceratocone e as transcrições foram submetidas à análise de conteúdo, modalidade temática. Resultados: As transcrições permitiram a formação de duas categorias: Vivenciando a doença e Mudança de vida após a cirurgia. A primeira elencou a vivência do paciente com ceratocone, dificuldades enfrentadas, adaptações necessárias, busca por recursos e frustrações e a segunda categoria destaca os anseios relacionados ao processo cirúrgico, seguida da esperança de encontrar a solução, sendo a cirurgia considerada como algo miraculoso, pois permitiu a reinserção na sociedade e trouxe de volta o sentido da existência. Conclusão: Os pacientes submetidos à cirurgia de ceratocone descreveram que a cirurgia promoveu a melhora da autoestima e do amor-próprio, trazendo de volta o sentido da vida que haviam perdido.

Descritores: Ceratocone/cirurgia; Procedimentos cirúrgicos ambulatoriais; Qualidade de vida

\footnotetext{
${ }^{1}$ Centro Universitário de Maringá - Unicesumar. Maringá (PR), Brazil.

2 Hospital de Olhos de Rondonópolis, Rondonópolis (MT), Brazil.

The authors declare no conflicts of interests.

Received for publication 25/05/2016 - Accepted for publication 20/08/2016
} 


\section{INTRODUCTION}

$\mathbf{T}$ The eye is one of the most complex organs in the human body, its primary function is to convert light into electrical signals that can be understood by the brain.Although all the parts of the structure are important, the cornea provides most of the focusing power of the eye, thus playing a significant role in the formation of the image. ${ }^{(1)}$ The cornea comprises five layers:epithelium, Bowman's layer, stroma, Descemet's membrane, and endothelium. ${ }^{(2)}$

Among the various pathologies affecting the world population,Keratoconusdeserves attention once it reaches approximately 50 to $230 / 100,000$ in the general population, affecting men and women in equal proportion, in $90 \%$ of cases affecting both eyes.It generally develops asymmetrically, leading to impairment of sight.The diagnosis of the disease in the second eye occurs about five years after the diagnosis in the first eye..$^{(3)}$

The loss of visual capacity entails adverse consequences at individual and collective level, giving rise to psychological, social and economic problems, because it implies a loss of self-esteem, social status, occupational restrictions and a consequent reduction of income.To society, it represents an important burden and loss of workforce.The visual deficit leads to a decrease in the quality of life, and is associated to higher rates of suicide in this population. ${ }^{(4)}$

Keratoconus patients presenting impairment of visual capacity tend to have their welfare and quality of life compromised, whereas individuals with satisfactory vision carry out activities of daily life autonomously, having improved quality of life..$^{(4,5)}$

Due to the high incidence of Keratoconus in the world population, ${ }^{(3)}$ and in the absence of great comparative information between corneal topography before and after treatment with intraestromal ring insertion ${ }^{(6)}$ and his subsequent association to the decrease of welfare ${ }^{(7)}$, it is worth mentioning the importance of studies addressing the changes in the life of the patient after Keratoconus surgery.Considering this gap, the present study aimed at knowing the repercussion of Keratoconus surgery on the patient's life.

\section{Methods}

We conducted a study of exploratory descriptive type, with a qualitative approach. We chose the qualitative research due to being adequate to the human experiments, responding better to the particularity of this research

It was held in the city of Rondonópolis(MT), which has been known for performing surgery on patients with Keratoconusat Hospital de Olhos de Rondonópolis. The choice of this scenario is due to the users of this health service have impaired vision and search for help to improve their quality of life.

The patients undergoingKeratoconussurgery were invited to participate in this study.Those who accepted signed an informed consent and cleared their doubts, and anonymity was guaranteedas well as the right to withdraw from the interview at any time.The patients were identified by using the letter $\mathrm{P}$ and the ID number, for example (P01).

The data was collected at Hospital de Olhos de Rondonópolis, and each patient was interviewed individually, in a private room, with no contact with the external environment.The interview was recorded with prior consent of the participants, and started with questionsrelated to sociodemographic data (age, gender, education), followed by the guiding question:report the changes that have occurred in your life after surgery.

The interviews lasted 30 minutes on average, and at the end they were fully transcribed, with several readings and rereadings to avoid data loss, and afterthey were subjected to the content analysis process ${ }^{(8)}$. Data was analyzed by the researchers and was classified with the operations of encoding and decomposition, thus identifying the unit of meaning of each phrase, and associating those with the same meaning to form the thematic categories, making data meaningful way and valid.The sample followed the data saturation criterion, but from the moment the units of meaning started to repeat themselves the $\mathrm{N}$ of the sample was established.

The study complied with the formal requirements contained in the national and international regulatory standards for research involving human beings, with the approval of the Committee by opinion No. 743.552 .

\section{RESULTS}

This case study comprised six people, among which $50 \%$ $(n=3)$ were women and $50 \%(n=3)$ were men, and the average age of participants was 31 years. As for education, $66 \%(n=4)$ of participants reported having completedGraduation, $16 \%(\mathrm{n}=1)$ completed high school, and $16 \%(\mathrm{n}=1)$ had incomplete elementary school.Regarding the surgical procedure, $50 \%$ of patients $(n=3)$ were subject to surgery on the left eye, $34 \%$ on the right eye $(n=2)$, and $16 \%(n=1)$ on both eyes. When asked about religion, $66 \%(n=4)$ follow Catholicism and $33 \%(n=2)$ reported being Evangelicals.

The detailed analysis of the transcripts allowed the creation of two categories, the first expressing the experience of the patient with Keratoconus, the difficulties faced and the adaptation to the disease.The second category highlights the concerns related to the surgical procedure, followed by the hope of finding the cure, with the surgery being considereda miracle to some patients, because it allowed the reinsertion into society and brought back the meaning of existence to one of the patients.

\section{Category:Experiencing the disease}

Study participants reported situations they have experienced before surgery, describing their difficulties and weaknesses.It was expressed as follows:So in the past I saw, I always see, all my life I saw very badly, all so blurry,like when I could see well and I saw everything doubled when I could see.(P01) ... which I have since I was a kid, I've always had a lot of problems at school, like... seeing the board, carry out the activities, Inever had the opportunity to have a more specialized treatment. $(\mathrm{P} 02)$

Another patient emphasized how he discovered the disease, to him he didn't have difficulties to see, because one eye compensated the lack of sight that the other eye had; he describes this situation:I had a cold and by chance I closed the right eye and noticed that I almost could not see with the left eye, so I was worried and sought treatment because I was almost blind in the left eye. $(\mathrm{P} 03)$ Another patient reported already having problems to see: $a$ few years ago I was very uncomfortable about the issue of sight, both in my job - I work with computers, I am a store manager, and... I have to write reports, work, and I was uncomfortablewith that, my eyes burned, itched, and didn't know what it was. (P04)

Another patient reported that to him...The left eye was not so problematic, but the most uncomfortable was very right eye, a lot of discomfort.But it ends up affecting both, right? I think even 
Keratoconus was also developed in left eye due to such impairment in the right eye. $(\mathrm{P} 02)$

The disease brings with it difficulties that only those who know and experience it are able to identify.Some of the symptoms that the patient experience are distorted vision, irregular myopic astigmatism, and loss of visual acuity.One of the interviewed reported that: ... At first I walked crookedly on the street, and we figured it out when I started changingone food to the other.(P05) ...It was so uncomfortable... Besides the problem of myopia, visual impairment, I was very nervous during the appointments due to need to see...(P02)

The patient realizes he has distorted vision and that this difficulty begins to infer in his everyday activities, moreover, he starts to fear that this situation may private himfrom being active in society: I saw two figures, two figures, and when we walked, I walked on the street, you walked just right, and when you got scared you were already away from that path, you didn'tgo straight ahead, and from that moment I realized I was walking crooked.(P05) It was difficult to use the computer because... the monitor is bright disturbed too much my vision... to work in general.I had many problems, I've always had a lot of difficulty to be able to carry out the activities. $(\mathrm{P} 02)$

Another situation experienced was related to driving.The patient realizes that when the Sun is hot he has difficulty and he should avoid some hours that compromise his sight: ... in the period of lots of sunlight,like four, five o'clock in the afternoon here in Mato Grosso,it starts to get cloudy, and I saw it wouldn't be so safe to drive, that's it.(P03) Any sunlight in my eyes. So, when I was out during the day, there was sunlight in my eyesdisturbing a lot, driving was terrible.(P02) I didn't drive...especially at night, Ionly drove during the day, at night I didn't drive because at night I have a lot distance problems, like when I think something is far away and it's pretty close.( $\mathrm{P} 01)$

This way, the patient needs to adapt due to difficulties, so when he sees that his vision is impaired and he must continue to carry out his activities he can keep the organization of objects:it was all organized because I didn't know if I was going to be able to undergo this surgery, so I had already organized everything,all underwear along, my clothes, I've asked my partner not to change places because I would know where everything was.(P05)

The adaptation to the disease also involves the use of ocular prostheses that can assist the patient's sight, but some of those interviewed described that: ... I never got used to wearing glasses, I think the glasses gave me a headache and I saw worse with glasses, I couldn't see well with glasses.(P01) There was no way to... adjust the glasses, and I was with impaired vision for a long time. (P06) ...many times he started the treatment with glasses, he prescribed glasses for me, he said it was the first step of treatment, trying to stabilize it. (P04)

It was further reported that they tried to wear lenses: ... I tried the lens, I wore glasses for a while (P03), but they failed to adapt:I just couldn't get used to the lens on the other eye because I wore rigid lens, which very very uncomfortable... I could not get used to the lens.(P01) I just couldn't adapt to the lens... before I had the ring implanted, I tried to wear the rigid lens, I could not adapt, I think it was due to being very sharp, you know....(P02)

So it was clear that when the situation lasts a few months and the difficulties are more often the patient's self-esteem tends to decrease, and this can reflect in an extremely negative way: the patient loses his self-respect and faces depression that can lead to suicidal thoughts and feeling of uselessness:Before the surgery I even thought of killing myself, actually I didn't get to this point because I have a fourteen year old child, and I don't know who would take care of her, I mean, the family, but it wouldn't be like her mother, so I faced that at house.(P05)

\section{Category:Change of life after surgery}

When diagnosed with Keratoconus, many thoughts can come to the patient's mind, as is something unknown, something that involves emotion as sight is considered extremely important in a person's life.The initial behavior of that person can be heartbreaking, because they tends to be in shock to know they need to undergo a surgical procedure:The moment I knew I really needed the surgery was when I got in shock.(P05) Then, the patient starts being hopeful about the procedure:Last year he had a checked-up, and found out the cornea was also getting thinner, and then he told me it would be necessary to implant the ring... to reduce that and see try to stabilize it. ( $\mathrm{P} 04)$...One day (laughter) the lady called me saying that there was this, this new proposal, to implant the ring.(P06)

After this initial moment, the patient realizes that the surgery can bring back the meaning of their life:but it was a solution that came to us here.It was the solution, then we ran after that, it was a success, you know, so it was really worth it, I recommend to everybody in need.(P05). She reports that:I live again, I am so grateful to people directly and indirectly involved with the successful work of the doctor.(P05) ...it was very good, a great change like... it was like... as soon as it started he called me and we set everything, and it has been, I liked it very much, I'm really satisfied.(P06)

Patients undergoing surgery began to seek knowledge to know what type procedure that would be carried out:I was subject to the ring implant procedure ( $\mathrm{P} 03)$.... I could have...this ring implant surgery, right, the ring of Ferrara.(P02)

Thus, he reported that after the ring implant his vision has improved:I ended up having the ring implanted, it improved a lot, but my routine didn't change a lot because the right eye used to compensate for what the left one couldn't see.(P03) After surgery, I had a great improvement, my vision was morecomfortable, ...itimproved a lot to meafter surgery, now I see a possibility of even greater improvement, alreadyhaving the lens correction, the last exam showed me that my vision can improve a lot more.(P02)

One of the patients noticed the difference immediately after the surgical procedure:Then he made this implant, the surgery, and in the first days I even asked him, "hey doctor, what happened?"Because it was a very big difference, the first impact is like this... my sight is completely changed.(P03) Butanother case took a longer time:So... in everything, everything was improved. ... in three months I could see the result.(P06)

The surgery brought back to the patient the opportunities of life, generating increased self-esteem, autonomy, and an unforgettable experience: ... after the surgery I come and go easily, really.(P05). Another one reported improvement in the reading and use of electronics:but it has already improved a lot, even readingis better, I think it is about $70 \%$ better. It is also better at work because I work a lot with computers, and it'salso much better.(P01)

In addition, the surgery allowed the patient to go back to his daily activities:Today I see well, work well with the computer, which is one of the areas that I'mstill developing, like maintenance and other things that require a lot of vision. ... in traffic!Wow, in traffic it is much better... traffic signs, traveling, road marks, it was very difficult to travel at night.(P02) 


\section{DisCUSSION}

The transcripts expressed in the first category how patients diagnosed Keratoconus, how they realized the difficulties to see, and how this symptom was worsening over time, leading to loss of vision or distorted vision.

Research describes that early diagnosis of Keratoconus is difficult, and may go unnoticed unless a corneal topographyis made.The earliest symptom of this disease is increased corneal curvature, which causes irregular myopic astigmatism, and the ocular signs and symptoms vary according to the severity of the disease. ${ }^{(2)}$ The progression of the disease is manifested as loss of visual acuity, and in advanced cases the diagnosis becomes obvious when the patient looks down and the lower eyelid is deformed by the protrusion of the cornea (Munson signal). ${ }^{(6)}$

For the diagnostic evaluation, various equipmentis used both in the diagnostic aid and theprogression follow-up of corneal disorders, in addition to preoperative assessment.The computed videokeratography evaluates the corneal curvature as a reflector mirror, capturing the keratoscopicimage produced by the disk with concentric rings. ${ }^{(9)}$

Patients diagnosed with Keratoconus reported that due to the symptoms of the disease it was difficultto carry out the daily activities.The visual loss led patients to present functional losses, limiting and restricting the participation and performance in everyday activities, interfering in independence, autonomy and quality of life that they had. ${ }^{(10)}$

This way, participants described they tried to adapt to the difficulties, and tried to wear eye prosthesis, however they did not work as expected.Research describes that incipient cases are controlled with glasses, contact lenses may be used in mild cases, and more severe cases may be treated with deep anterior lamellar keratoplasty and corneal transplant.However, it depends on each individual's adaptation to the use of prosthesis. ${ }^{(2)}$

Other research shows that the use of resources has been proved beneficial to the expansion of functionality, showing the influence of external factors on the performance of the individual. ${ }^{(11)}$ However, some patients reported being dissatisfied with the use of glasses and contact lenses, because they interfere in aesthetics and in sports activities, and require a lot of care to be handled.Besides, they are more frustrating, decrease selfconfidence, emotional and professional success, and worsen the quality of life. ${ }^{(11)}$

A study describes the visual condition of the patient, in the search for a variety of resources that can ameliorate the practical problems in that the subject seeks the most appropriate or feasible one. ${ }^{(12)} \mathrm{A}$ survey reiterates the benefits that people with Keratoconus can conquer when being part of rehabilitation programs aiming to promote autonomy and independence. ${ }^{(7)}$

Researchers report that impaired vision can affect the reduction of welfare, while a better visual acuity and various factors related to daily life are related to an improvement in the quality of life of this population. ${ }^{(4)}$ It was expressed by one of the participants whoforgot the meaning of her existencewhen she lostsight, leading to depressive symptoms and suicidal thoughts.However, after surgery, new horizons have emerged and gave the meaning of life back to her.

The second category shows this repercussion of surgery in the lives of patients, with the anxietyat the discovery of the necessity of the procedurebeing reported.A study demonstrates that patients had emotional stress before surgery due to the concern about the surgery and its result. ${ }^{(12)}$
However, after the surgery, the participants reported improved self-esteem, and reinsertion to society.The surgery for the treatment of Keratoconus allows rehabilitate patients to their dailyactivities $^{(13,14)}$, which represents a considerable social and economic gain, considering that the incidence occurs between 10 and years of age, a phase of high-productivity of the individuals. ${ }^{(6)}$

Studies have demonstrated the effectiveness of surgery for Keratoconus in the lives of individuals, but claim that the subject is still incipient in the scientific world, requiring further studies reporting the safety and benefits of this procedure. ${ }^{(15-17)}$

Other research showed that patients undergoing surgery improved the quality of life and decreased psychological stress. ${ }^{(12,18,19)}$ When the questionnaire was applied, it showed improvement in mental health, and the authors claim that it was probably because the patients were less frustrated, irritable, and with less ocular pain. ${ }^{(12,19)}$

Authors state that in addition to the statistically significant difference in the correctedvisual acuity, Keratoconus surgery gives the patient better quality of life, and glasses can also be a tool to cases in which it was not possible to recover full sight. ${ }^{(20)}$

In addition, it is up to professionals to give the appropriate information, solve doubts and desires so that patients understand the role of surgery, minimizing unrealistic expectations of total elimination of refractive errors. ${ }^{(20)}$

\section{Final Considerations}

The study allowed unveiling the experience of patients with Keratoconus, their difficulties, adjustments needed to maintain the quality of life.Besides, it was highlighted the concerns related to the surgical procedure, the surgery being considered by some as something miraculous, because it allowed reinsertion in society.

With a sharper look we can see that the surgery has promoted the improvement of self-esteem, bringing back the meaning of life they had lost.And even if it isn't mentioned by participants in the transcripts, we realized they believed in an inner force making them seek a meaning to their existence.New studies are needed, as this one does not reflect reality, but was able to show that Keratoconus surgery brought numerous benefits to patients who have undergone this procedure.

\section{RefERENCES}

1. Ambekar R, Toussaint KC Jr, Wagoner Johnson A. The effect of keratoconus on the structural, mechanical, and optical properties of the cornea. J Mech Behav Biomed Mater. 2011;4(3):223-36.

2. Romero-Jiménez M, Santodomingo-Rubido J, Wolffsohn JS. Keratoconus: a review. Cont Lens Anterior Eye. 2010;33(4):157-66; quiz 205.Review.

3. Tardin JR, Bastos MA, Borges KS. Resultado biomecânico, topográfico e anatômico pós-anel intraestromal em ceratocone avançado. Rev Bras Oftalmol. 2013; 72 (4): 268-70.

4. Bravo Filho VT, Ventura RU, Brandt CT, Sarteschi C, Ventura MC. Impacto do déficit visual na qualidade de vida em idosos usuários do sistema único de saúde vivendo no sertão de Pernambuco. Arq Bras Oftalmol. 2012; 7 (3):161-5.

5. Borelli M, Rehder JR, Squarcino IM, Gonçalves AM, Piaia FA, Fernandes PK, et al. Avaliação da qualidade da visão, na prática da leitura diária, em relação à formatação dos textos. Rev Bras Oftalmol. 2010; 69 (2):114-20.

6. Miranda D, Campos M. Ceratocone. Rev Bras Oftalmol. 2004;63(9-10):503-12. 
7. Becker P, Montilha RC. Ocupational performance and quality of life: interrelationships in daily life of visual impaired individuals. Rev Bras Oftalmol. 2015; 74(6):372-7.

8. Bardin L. Análise de conteúdo. São Paulo: Edições 70; 2011. 229p.

9. Kuntz J, Luz A, Dalfré JT, Simões DO, Grupenmacher L, Barbosa de Sousa L. Comparação entre dois sistemas de análise de topografia corneana. Rev Bras Oftalmol. 2012; 71(4):233-5.

10. Silva MR. Visual impairment, rehabilitation and International Classification of Functioning, Disability and Health. Rev Bras Oftalmol. 2014; 73(5):291-301.

11. Laplane AL, Batista CG. To see, not to see and to learn: the participation of low vision and blind children at school. Cad Cedes. 2008; 28(75):209-27.

12. Belfort R, Campos M, Hoexter MQ, Belfort Jr R, Mari JJ. The impact of photorefractive excimer laser keratectomy (PRK) and laser in situ keratomileusis (LASIK) on visual quality and life in patients with ametropia. Arq Bras Oftalmol. 2008;71(1):83-9.

13. Horovitz RN, Garcia R, Bechara SJ. Crosslinking: an updated and effective insight. Rev Bras Oftalmol. 2015; 74 (2): 119-23.

14. Tuwairqi WS, Sinjab MM. Safety and efficacy of simultaneous corneal collagen cross-linking with topography-guided PRK in managing low-grade keratoconus: 1-year follow-up. J Refract Surg. 2012; 28(5): 341-5.

15. Celik HU, Alagoz N, Yildirim Y, Agca A, Marshall J, Demirok A, Yilmaz OF. Accelerated corneal crosslinking concurrent with laser in situ keratomileusis. J Cataract Refract Surg. 2012; 38(8):1424-31.
16. Vega-Estrada A, Alió JL, Puche ABP, Marshall J. Outcomes of a new microwave procedure followed by accelerated cross-linking for the treatment of keratoconus: a pilot study. J Refract Surg. 2012; 28(11):787-92.

17. Touboul D, Efron N, Smadja D, Praud D, Malet F, Colin J. Corneal confocal microscopy following conventional, tranepitelial, and accelerated corneal collagen cross-linking procedures for keratoconus. J Refract Surg. 2012; 28(11):769-75.

18. Freitas C, Oliveiros BM, Marques E, Leite EB. Effect of photorefractive keratectomy on visual functioning and quality of life. J Refract Surg. 1995; 11(3 Suppl):327-34.

19. Ambrosio Junior R. Therapeutic refractive surgery: Why we should differentiate? Rev Bras Oftalmol. 2013; 72(2):85-6.

20. Ambrosio Junior R, Borges JS, Ferreira CC, Coelho V, Silva RS, Valbon B, et al. Intrastromal corneal ring segments for keratoconus: results and correlation with preoperative corneal biomechanics. Rev Bras Oftalmol. 2012; 71

\section{Corresponding author:}

Laura Ligiana Dias Szerwieski.

Avenida Guedner, n¹610, Jardim aclimação, Maringá (PR), ZIP Code: 87050-390.

Programa de Mestrado, Bloco 7 Centro Universitário

Maringá - Unicesumar

Email: laura.enfer@gmail.com. 